\title{
Pré-tratamento com água e doses de ácido indolbutírico para estaquia herbácea de pitangueiras
}

\author{
Pre-treatments with water and indole butyric acid dosis for herbaceous cuttings of Surinam cherry
}

\author{
Daiane Silva Lattuada ${ }^{\mathrm{I}}$ Mônica Spier ${ }^{\mathrm{I}}$ Paulo Vitor Dutra de Souza ${ }^{\mathrm{II}}$
}

\section{RESUMO}

No Brasil, a maioria dos pomares de pitangueira (Eugenia uniflora) é formada por mudas do tipo pé-franco,o que torna os plantios com baixa uniformidade genética. A propagação vegetativa via estaquia é uma alternativa viável para propagação de diversas espécies frutíferas, podendo ser utilizada também com as espécies nativas, proporcionando a formação de pomares homogêneos, com a produção de mudas com alta sanidade, além de antecipar a produção. Nesse contexto, conduziu-se um estudo visando à multiplicação vegetativa da pitangueira, em que se testou a estaquia herbácea a partir de estacas coletadas de plantas matrizes jovens e adultas, submetidas a três períodos de imersão em água $(0,24$ ou 48 horas), além da aplicação de doses de ácido indolbutírico $\left(0,2000,4000\right.$ e $\left.6000 \mathrm{mg} \mathrm{L}^{-1}\right)$. Foram avaliadas a sobrevivência (\%), a retenção e a emissão foliar ( $n^{\circ}$ folhas/ estaca), a calogênese (\%) e enraizamento das estacas (\%). Ao final do experimento, avaliou-se massa fresca e seca de parte aérea e raiz, número de folhas e área foliar. $O$ delineamento experimental foi o completamente casualizado, com três repetições de dez plantas por tratamento para os parâmetros não destrutivos e três repetições de cinco plantas por tratamento para os parâmetros destrutivos. A estaquia herbácea foi eficiente para produzir mudas de pitangueira, especialmente quando utilizadas estacas oriundas de plantas jovens sem necessidade de pré-lavagem nem adição de auxinas exógenas.

Palavras-chave: propagação vegetativa, auxinas, idade, Eugenia uniflora.

\section{ABSTRACT}

In Brazil, most of the Surinam cherry (Eugenia uniflora) orchards is formed by ungrafted plants, which makes the plantations have low genetic uniformity. The vegetative minicutting propagation is a viable alternative for the propagation of several fruit species, and can also be used with native species providing the formation of orchards with homogeneous populations of plants, with production of seedlings with high health and accelerated propagation process. In this context, a study for the multiplication of Surinam cherry was conduced with herbaceous cuttings, taken from young and adult mother plants, immersed in indole butyric acid doses $(0$, 2000, 4000 and $6000 \mathrm{mg} \mathrm{L}^{-1}$ ), in three different water periods (0, 24 or 48 hours). Survival rate (\%), leaf retention and emission (No. leaves /cutting), callus rate (\%) and rooting (\%) were evaluated. At the end of the experiment, were also evaluated fresh and dry weight of shoot and root, leaf number and leaf area. The experiment has a completely randomized design with three replications of ten plants per treatment for nom destructive and three replications of five plants per treatment for the destrutive parameters. The herbaceous cuttings were efficient to produce seedlings of Surinam cherry, particularly when using cuttings derived from seedlings in the absence of the immersion in water and exogenous auxin.

Key words: vegetative propagation, auxins, age, Eugenia uniflora.

\section{INTRODUÇÃO}

A pitangueira (Eugenia uniflora) é uma importante representante das Myrtaceae e é encontrada na Argentina, Paraguai, Uruguai e no Brasil. Neste último, é distribuída da Bahia ao Rio Grande do Sul, ocorrendo em todas as formações vegetais desses Estados. É uma espécie frutífera e ornamental, podendo ser incluída em projetos de revegetação de áreas

'Programa de Pós-graduação em Fitotecnia, Universidade Federal do Rio grande do Sul (UFRGS), Porto Alegre, RS, Brasil

"Departamento de Horticultura e Silvicultura, UFRGS, 91540-000, Porto Alegre, RS, Brasil. E-mail: daialattuada@gmail.com. Autor para correspondência 
degradadas (BACKES \& IRGANG, 2002), além de apresentar potencial para ser utilizada pelas indústrias farmacêuticas e de cosméticos.

No Brasil, os primeiros plantios comerciais de pitangueira aconteceram na região de Bonito, no agreste pernambucano, que atualmente conta com uma área de 150ha cultivados com a cultura, sendo sua produção destinada à indústria de sucos (SEAGRI, 2011). Estes pomares foram formados por mudas do tipo pé-franco, ou seja, resultantes da propagação por sementes. Mudas assim propagadas não são recomendadas para a formação de pomares comerciais, pois, além de retardar o início da produção de frutos, permitem o desenvolvimento de plantas desuniformes, quanto ao crescimento, floração e frutificação, dificultando as atividades de manejo da cultura, inclusive a própria colheita (LIRA JÚNIOR et al., 2007). Considerando-se a expansão e o elevado potencial de cultivo agroindustrial da pitangueira, recomenda-se a substituição de pés-francos por mudas propagadas vegetativamente (BEZERRA et al., 2000).

A propagação vegetativa é uma importante ferramenta no melhoramento de espécies lenhosas e herbáceas e vem sendo amplamente utilizada, visando a melhorar e manter variedades de importância econômica e medicinal (EHLERT et al., 2004). Na fruticultura, a estaquia vem sendo largamente utilizada na produção comercial de mudas, com boa qualidade e em curto espaço de tempo, pois garante a manutenção de características varietais, como uniformidade, produção, qualidade do fruto, precocidade e sanidade (FACHINELLO et al., 2005).

O processo de formação de raízes em estacas é influenciado por um grande número de fatores, que podem atuar isoladamente ou em conjunto. Dentre esses, destacam-se a idade e as condições fisiológicas da planta matriz (presença de carboidratos, substâncias nitrogenadas, aminoácidos, auxinas, compostos fenólicos e outras substâncias não identificadas), o período de coleta das estacas, a posição destas nos ramos, sua juvenilidade, o estiolamento e/ou a presença de folhas e gemas e os fatores do ambiente, como disponibilidade de água, luminosidade e substrato (HARTMANN et al., 2002; DUTRA et al., 2002).

No entanto, um dos maiores entraves para a emissão de raízes, especialmente nas espécies pertencentes às Myrtaceae, está na oxidação de compostos fenólicos, fenômeno responsável pela liberação de exsudados tóxicos ao tecido da estaca, observado no ponto de corte e que prejudica o enraizamento. Segundo CAMPOS et al. (2005), uma das possíveis técnicas para reduzir o efeito desses compostos é a lavagem das estacas em água, pois auxilia na lixiviação de alguns compostos fenólicos, evitando assim as oxidações. De acordo com GALETI et al. (2010), a técnica de imersão por 24 horas em água para estaquia de amoreira é bastante difundida entre os sericultores, pois através dela pode-se lixiviar as substâncias inibidoras do enraizamento, além de ser uma metodologia simples de aplicar e que não acarreta custo adicional ao sistema produtivo.

A idade das plantas matrizes é outro fator determinante ao sucesso da estaquia. Em geral, estacas provenientes de material vegetativo juvenil enraízam com maior facilidade, especialmente em espécies de difícil enraizamento. Possivelmente, devido ao aumento no conteúdo de inibidores e à diminuição de cofatores, à medida que aumenta a idade da planta. Dessa forma, é recomendável a coleta de brotações jovens em plantas adultas, as quais, mesmo não caracterizando uma verdadeira condição de juvenilidade, têm mais facilidade de enraizamento (FACHINELLO et al., 2005). Ainda segundo este autor, estacas coletadas no período de crescimento vegetativo intenso (primavera/ verão) apresentam estruturas herbáceas que oferecem maior capacidade de enraizamento.

A indução para formação do sistema radicular é estimulada pela ação do ácido indolacético (AIA), que atua em conjunto com carboidratos, compostos nitrogenados e vitaminas. Com o mesmo efeito, podem-se utilizar substâncias químicas sintéticas como o AIA (ácido indolacético), o ANA (ácido naftalenoacético) e o AIB (ácido indolbutírico), com o objetivo de aumentar a porcentagem e a qualidade das raízes, além de acelerar e uniformizar o enraizamento (OLIVEIRA et al., 2001).

Diferentes espécies pertencentes à Myrtaceae foram estudadas quanto ao enraizamento de estacas tratadas com AIB, dentre elas a jaboticabeira (Myrciaria jabuticada), por SCARPARE FILHO et al. (1999), a goiabeira-serrana (Acca sellowiana) e o guabijuzeiro (Myrcianthes pungens), por FRANZON (2004), e a cerejeira-do-mato (E. involucrata D.C.), a pitangueira (E. uniflora L.) e a grumixameira $(\boldsymbol{E}$. brasiliensis Lam), por LOPES (2009), os quais não obtiveram sucesso no enraizamento de estacas dessas espécies.

Diante disso, realizou-se um experimento testando a influência da origem das estacas, seu período de imersão em água e doses de AIB, buscando viabilizar a propagação vegetativa de pitangueira.

\section{MATERIAL E MÉTODOS}

Estacas herbáceas de pitangueira foram coletadas de plantas matrizes juvenis (três anos de idade), 
cultivadas em recipientes (sacos de polietileno preto de $5 \mathrm{~L}$, contendo substrato à base de resíduo decomposto de casca de acácia, solo São Jerônimo, casca de arroz carbonizada e areia média nas proporções 1:1:2:2 -v:v-, respectivamente) e em casa de vegetação, e de plantas adultas e produtivas (dez anos de idade), cultivadas a céu aberto em Porto Alegre ( $30^{\circ} 1$ '27,90”S e $51^{\circ} 11^{\prime} 22,92^{\prime \prime} \mathrm{O}, 46,97 \mathrm{~m}$ de altitude).

As estacas foram coletadas em setembro de 2009, selecionadas quanto ao seu diâmetro ( 1 a $2 \mathrm{~mm}$ cada estaca) e comprimento (aproximadamente $5 \mathrm{~cm}$ ), sendo mantidas duas metades de folhas opostas na porção superior de cada estaca. As estacas foram totalmente imersas em água por três distintos tempos de imersão (zero, 24 e 48 horas), para lixiviação dos compostos fenólicos. Após esses períodos, na base das estacas, realizou-se um corte em bisel com auxílio de bisturi, visando a expor o câmbio e imergiu-se por 10 segundos em soluções de auxina testadas no experimento. Foram testadas quatros doses de soluções hidroalcoolicas de ácido indolbutírico (AIB): zero, 2000, 4000 e $6000 \mathrm{mg} \mathrm{L}^{-1}$. Dessa forma, o experimento consistiu-se de 24 tratamentos a partir de três fatores (idade da planta matriz, tempo de imersão das estacas em água e doses de AIB), usando-se 10 estacas por parcela em três repetições. O delineamento experimental adotado foi o completamente casualizado, sendo composto por três repetições de 10 estacas cada.

Após aplicação dos tratamentos, as estacas foram colocadas em bandejas multicelulares com 124 células de $120 \mathrm{~cm}^{3}$ cada célula, preenchidas com casca de arroz carbonizada (CAC). O experimento foi mantido em câmara de nebulização intermitente (aspersão por um minuto a cada 20 minutos). A umidade relativa do ar esteve a $90 \% \pm 5 \%$ e a temperatura média foi de $21^{\circ} \mathrm{C}$, durante o período do experimento (setembro a dezembro de 2009).

Após 70 dias da instalação do experimento, avaliou-se o percentual de sobrevivência das estacas, a retenção e emissão foliar (número de folhas/estaca) e o percentual de calogênese e enraizamento das estacas. Metade das estacas enraizadas foram destruídas para análise dos parâmetros de crescimento das mudas como massa fresca e massa seca de parte aérea e raiz (g), número de folhas por planta e a área foliar por planta $\left(\mathrm{cm}^{2}\right)$, medida através de um medidor de área marca LICor, modelo LI - 3100. O acúmulo de massa seca das raízes e parte aérea por planta foi obtido pela secagem em estufa, com temperatura de $65^{\circ} \mathrm{C}$, até atingir peso constante. O restante das mudas foi transplantado para recipientes maiores para avaliações futuras.

Os resultados foram submetidos à análise de variância, sendo as médias (dados transformados $\sqrt{ } \mathrm{x}+10)$ diferenciadas estatisticamente pelo teste de Duncan $(\mathrm{P}>0,05)$ ou análise de regressão.

\section{RESULTADOS E DISCUSSÃO}

O enraizamento das estacas somente foi observado em estacas de plantas jovens (Tabela 1), sendo superior na ausência do tratamento de imersão, independente da dose de AIB utilizada (Tabela 1).

Tabela 1 - Enraizamento e calogênese em estacas herbáceas de pitangueira obtidas a partir de plantas jovens e de uma adulta, submetidas a tempos de pré-lavagem e doses de ácido indolbutírico (AIB). Porto Alegre, 2009.

\begin{tabular}{|c|c|c|c|c|c|c|c|}
\hline \multirow[t]{2}{*}{ Tratamentos } & \multicolumn{5}{|c|}{ - } & \multicolumn{2}{|c|}{-------Tempo de pré-lavagem (horas)------- } \\
\hline & 0 & 2000 & 4000 & 6000 & Média & 0 & 24 \\
\hline Adulta & 0,00 & 0,00 & 0,00 & 0,00 & $0,00 \mathrm{~b}$ & $0,00 \mathrm{Ab}$ & $0,00 \mathrm{Ab}$ \\
\hline Jovem & 36,09 & 44,15 & 38,79 & 35,82 & $38,66 \mathrm{a}$ & $69,07 \mathrm{Aa}$ & $15,59 \mathrm{Ba}$ \\
\hline Média & 14,75 & 17,67 & 15,74 & 14,65 & & & \\
\hline $\mathrm{CV} \%$ & \multicolumn{7}{|c|}{33,60} \\
\hline \multirow[t]{2}{*}{ Tratamentos } & \multicolumn{5}{|c|}{-Doses de AIB $\left(\mathrm{mg} \mathrm{L}^{-1}\right)$} & \multicolumn{2}{|c|}{------Tempo de pré-lavagem (horas) ----- } \\
\hline & 0 & 2000 & & 4000 & 6000 & 0 & 24 \\
\hline Adulta & $34,14 \mathrm{a}$ & $0,00 \mathrm{~b}$ & & $0,00 \mathrm{~b}$ & $0,00 \mathrm{~b}$ & 9,67 & 3,16 \\
\hline Jovem & $7,63 b$ & $0,00 \mathrm{~b}$ & & $2,58 \mathrm{~b}$ & $0,00 \mathrm{~b}$ & 5,00 & 0,00 \\
\hline Média & & & & & & $7,26 \mathrm{a}$ & $1,58 \mathrm{~b}$ \\
\hline $\mathrm{CV} \%$ & \multicolumn{7}{|c|}{33,87} \\
\hline
\end{tabular}

Médias seguidas de distintas letras maiúscula na linha e minúscula na coluna diferem significativamente pelo teste de Duncan (P>0,05). Dados transformados $\sqrt{(x+10)}$. 
A interação entre a idade da planta matriz jovem e a ausência de pré-lavagem foram os tratamentos mais promissores com $69,07 \%$ de enraizamento. Possivelmente, a juvenilidade da planta matriz tenha contribuído positivamente para esse resultado.

Diante desses resultados, observa-se que a imersão em água não traz benefícios ao enraizamento para pitangueira, o que difere do resultado obtido por CAMPOS et al. (2005) com mirtileiro, já que a imersão propiciou o enraizamento de até $90 \%$ das estacas.

A ausência de enraizamento nas estacas oriundas de planta adulta pode ter ocorrido devido às condições de ambiente em que se encontrava a planta e a esta estar em florescimento, quando a maioria das reservas das plantas são destinadas para a produção de flores. Embora a matriz adulta receba adubação anual, conforme indicação para a espécie, esta planta encontra-se mais vulnerável para desbalanços hídricos e de temperatura que as plantas em casa de vegetação. Comportamento similar foi observado por SASSO (2009), propagando a jabuticabeira Açú (Myrciaria sp.) por estacas apicais herbáceas $(10 \mathrm{~cm})$ coletadas no término da frutificação, em que obteve $7,1 \%$ de enraizamento. $\mathrm{O}$ autor relacionou este fato à menor concentração de reservas da planta-matriz, devido ao estádio fenológico que ela se encontrava no momento da coleta das estacas.

Houve interação entre as doses de AIB testadas e a idade da planta matriz para a calogênese das estacas sobreviventes, sendo os tratamentos estaca de planta adulta e $0 \mathrm{mg} \mathrm{L}^{-1}$ a combinação que apresentou maior proliferação de calos $(34,14 \%)$ (Tabela 1). Nas estacas provenientes de plantas jovens, somente 7,6\% formaram calo na ausência de AIB e quando este foi aplicado praticamente não houve formação de calos. Não houve interação significativa para idade da planta matriz e tempo de imersão das estacas para a calogênese das estacas, sendo a imersão prejudicial para este parâmetro (Tabela 1). Resultado diferente foi observado por LOPES (2009) em dois ensaios com as espécies de cerejeira-do-mato $(\boldsymbol{E}$. involucrata D.C.), pitangueira (E. uniflora L.) e grumixameira (E. brasiliensis Lam), em que ocorreu a formação de calos nas estacas sobreviventes (média de $90,5 \%$ em pitangueira e $85 \%$ em grumixameira), independente da dose de AIB utilizada, encontrando raiz somente em $6,67 \%$ nas estacas de cerejeira-do-mato tratadas com 500 e $1000 \mathrm{mg} \mathrm{L}^{-1}$ deAIB. Da mesma forma, FRANZON (2004) observou, em seu estudo com estacas herbáceas de distintos tamanhos de goiabeiraserrana, que as concentrações de AIB testadas (0, 2000, 4000 , 8000 $\mathrm{mg} \mathrm{L}^{-1}$ ) não propiciaram o aumento na formação de calo e nem a formação de raízes.
Segundo HARTMANN et al. (2002), quando as estacas são colocadas em condições de enraizamento, comumente ocorre a formação de calos, os quais são massas irregulares de células parenquimáticas em diferentes estágios de lignificação, através dos quais as raízes emergem. Porém, a formação das raízes adventícias e dos calos é independente e sua ocorrência simultânea se explica pelo fato de ambos envolverem processo de divisão celular, o que pode depender de condições internas e ambientais similares.

Diferentemente de GALETI et al. (2010), que para amoreira obtiveram maior sobrevivência de estacas após imersão em água, neste estudo, esse tratamento prejudicou a sobrevivência das estacas, sendo que a imersão em água por 48 horas causou a mortalidade de todas as estacas ainda nas primeiras semanas do experimento. Ao manterem-se as estacas por 24 horas imersas em água, somente $10 \%$ a $18 \%$ sobreviveram, enquanto que, sem imersão, entre $36 \%$ e $85 \%$ das estacas sobreviveram (Figura 1A). A permanência das estacas em uma condição de hipoxia pode ter desviado a respiração celular para uma rota fermentativa, acumulando etanol no tecido (SOUSA \& SODEK, 2002) e contribuindo assim para a mortalidade delas. A idade da planta matriz influenciou de forma significativa, sendo a maior sobrevivência observada em estacas obtidas de plantas jovens (60\%) (Figura 1A). Nas estacas provenientes de planta adulta, além de menor sobrevivência em relação às plantas jovens, houve interação com as doses de AIB, já que o aumento nas doses de auxina prejudicou a sobrevivência, com morte de $100 \%$ das estacas a partir de $2500 \mathrm{mg} \mathrm{L}^{-1}$ (Figura 1A). Apesar de a maior sobrevivência das estacas ser proveniente de plantas jovens, nestas também foi prejudicial o incremento das doses de AIB.

LOPES (2009), avaliando a propagação vegetativa por estaquia em mirtáceas, também verificou que a sobrevivência das estacas de pitangueira foi afetada negativamente pelo incremento nas doses de AIB, com percentual de sobrevivência similar ao atual estudo em ausência de auxina.

Estacas provenientes de plantas jovens retiveram mais folhas, comparado àquelas de plantas adultas (Figura 1B). A imersão das estacas em água prejudicou a sua retenção foliar, acarretando na queda de quase $100 \%$ das folhas (Figura 1B). A retenção foliar foi prejudicada linearmente pelo incremento nas doses de AIB, em estacas provenientes de planas jovens. Em estacas provenientes de plantas adultas e naquelas não imersas em água, a retenção foliar sofreu redução quadrática, saturando a resposta na dose de $2400 \mathrm{mg} \mathrm{L}^{-1}$ AIB. Segundo PASQUAL et al. (2001), é necessário que haja um balanço hormonal endógeno adequado, 


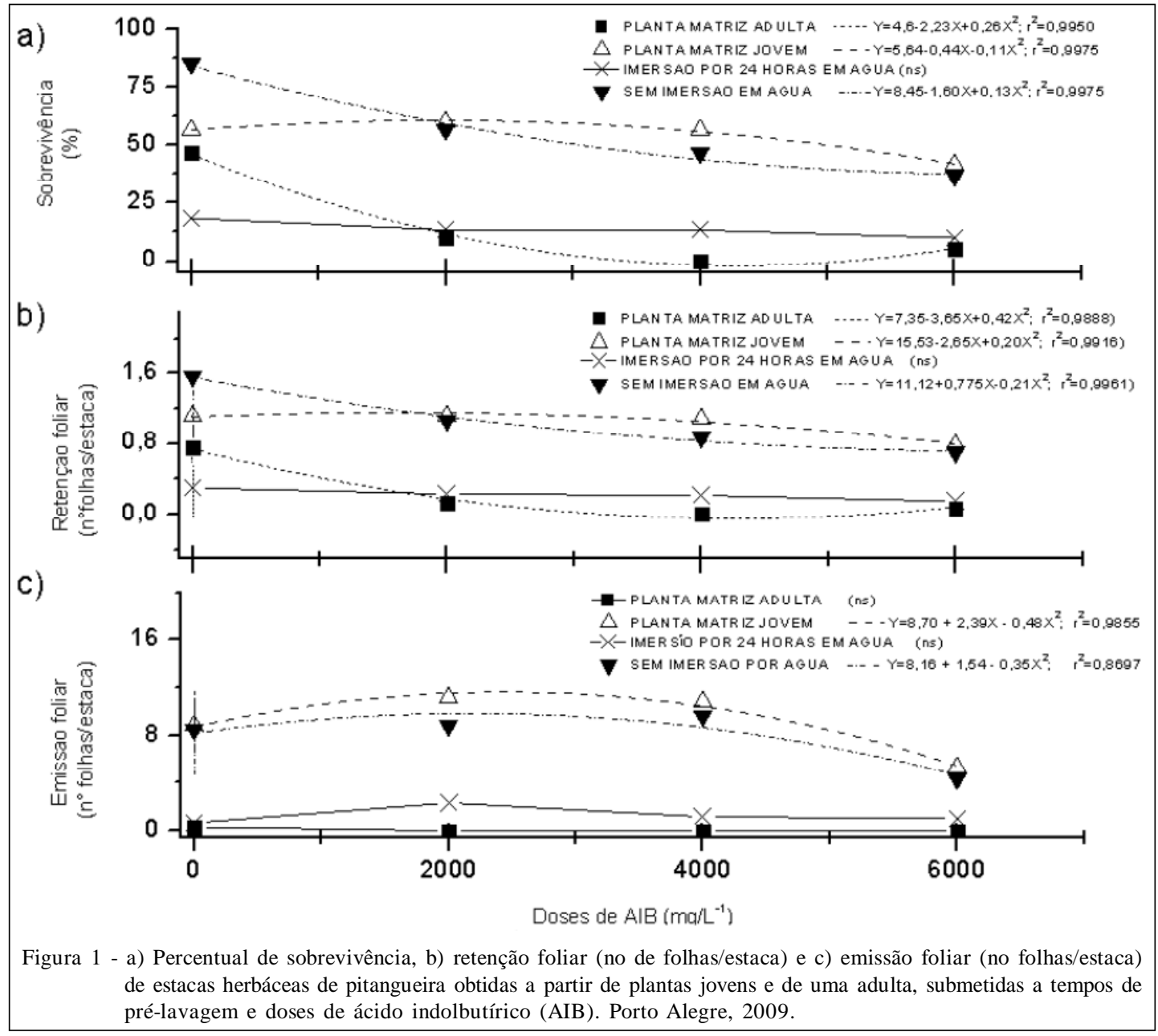

especialmente entre auxinas, giberelinas e citocininas, ou seja, equilíbrio entre promotores e inibidores do processo de iniciação radicial.

A emissão de folhas novas somente ocorreu em estacas provenientes de plantas jovens sem imersão em água (Figura 1C). Essa emissão, para ambos fatores, apresentou incremento no número de folhas até a dose de 2400 $\mathrm{m} \mathrm{L}^{-1}$, a partir da qual saturou, passando a ser prejudicial. Segundo TAIZ \& ZEIGER (2004), a resposta da planta à auxina endógena ou aplicada pode variar com a natureza do tecido e com a concentração desse regulador de crescimento já presente no propágulo. Aplicada em órgãos isolados, a auxina, dependendo de sua concentração, pode aumentar a resposta rizogênica até certo ponto, após o qual ocorre efeito inibitório.

NACHTIGAL et al. (1994), trabalhando com enraizamento de estacas herbáceas de araçazeiro (Psidium cattleyanum Sabine, Myrtaceae) em pleno crescimento vegetativo, observaram tendências à fitotoxidez, caracterizada pela queda de folhas, com aumento das concentrações de AIB. Os autores relacionam este fato com o efeito fitotóxico do AIB, principalmente pela formação de uma camada de abscisão foliar que provoca queda das folhas e posterior morte das estacas. Este efeito também foi verificado em goiabeira-serrana, o que influenciou negativamente na percentagem de sobrevivência de estacas (FRANZON, 2004).

As massas fresca e seca da parte aérea apresentaram respostas quadráticas positivas, com incremento até a dose de $2900 \mathrm{mg} \mathrm{L}^{-1}$ de AIB (Figura 2A e 2C) para aquelas estacas coletadas de plantas jovens. Já para aquelas coletadas de plantas adultas, a resposta foi quadrática negativa, em função da morte do material submetido a doses superiores a $2500 \mathrm{mg} \mathrm{L}^{-1}$ de AIB (Figura 2A e 2C). As doses de AIB utilizadas proporcionaram resposta quadrática para a massa seca de raiz com incremento até a dose de $2400 \mathrm{mg} \mathrm{L}^{-1} \mathrm{e}$ resposta não significativa para a massa fresca (Figura 2B e 2D). Na análise do número de folhas e área foliar (Figura 2F e 2E), as estacas de planta adulta 

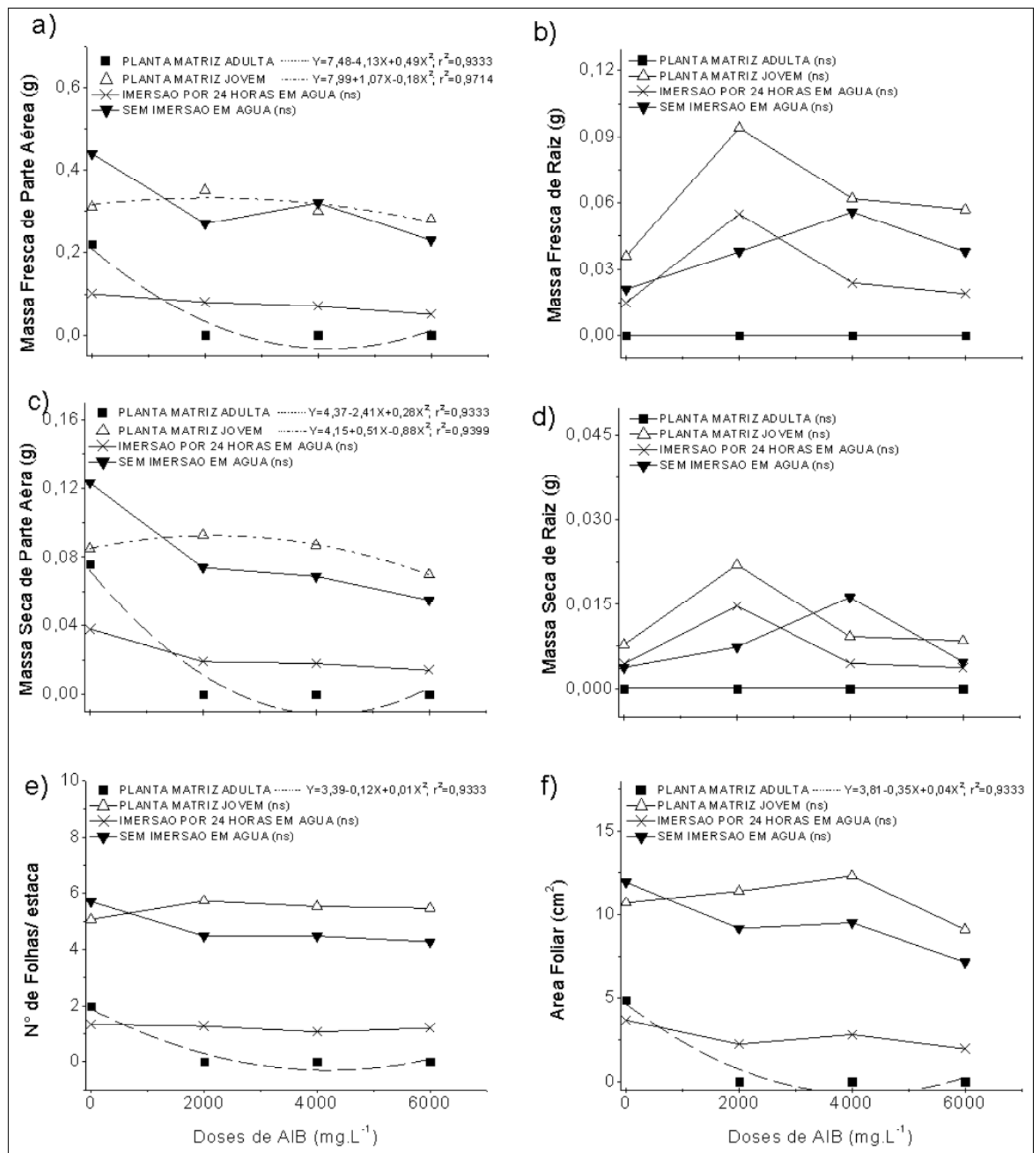

Figura 2 - a) Massa fresca de parte aérea, b) massa fresca de raiz, c) massa seca de parte aérea, d) massa seca de raiz, e) número de folhas por planta e f) área foliar de estacas herbáceas de pitangueira obtidas a partir de plantas jovens e de uma adulta, submetidas a tempos de pré-lavagem e doses de ácido indolbutírico (AIB). Porto Alegre, 2009.

apresentaram resposta quadrática negativa e, para o restante dos fatores, a resposta foi estatisticamente não significativa para as doses de AIB. A redução no acúmulo de massa fresca e seca das estacas e no número de folhas e da emissão foliar pode ser explicada pelo fato de as reservas nutricionais das estacas terem se esgotado no processo de enraizamento, à medida que se aumentou a dose de AIB utilizado.

\section{CONCLUSÃO}

A utilização de estacas herbáceas oriundas de pitangueiras jovens é viável, sem necessidade de 
pré-lavagem com água e tampouco da utilização de ácido indolbutírico.

\section{REFERÊNCIAS}

BACKES, P.; IRGANG, B. Árvores do Sul: guia de identificação $\&$ interesse ecológico. As principais espécies nativas sul-brasileiras. Porto Alegre: CD Vaz e Ricardo Correa, 2002. 332p.

BEZERRA, J.E.F. et al. Pitanga (Eugenia uniflora L.). Jaboticabal: FUNEP, 2000. 30p. (Série Frutas Nativas, 1).

CAMPOS, A.D. et al. Enraizamento de estacas de mirtilo provenientes de ramos lenhosos. Pelotas: EMBRAPA Clima Temperado, 2005. (Comunicado Técnico n.133). Disponível em: <http://www.cpact.embrapa.br/publicacoes/download/ comunicados/Comunicado_133.pdf $>$. Acesso em: 18 out. 2010.

DUTRA, L.F. et al. Época de coleta, ácido indolbutírico e triptofano no enraizamento de estacas de pessegueiro. Scientia Agrícola, Piracicaba, v.59, n.2, p.327-333, 2002. Disponível em: 〈http://www.scielo.br/pdf/sa/v59n2/8929.pdf〉. Acesso em: 20 mar. 2011. doi: 10.1590/S0103-90162002000200019.

FACHINELLO, J.C. et al. Propagação vegetativa por estaquia. In: FACHINELLO et al. Propagação de plantas frutíferas. Brasília: Embrapa Informação Tecnológica, 2005. p.69-108.

FRANZON, R.C. Caracterização de mirtáceas nativas do Sul do Brasil. 2004. 114f. Dissertação (Mestrado em agronomia) - Faculdade de Agronomia Eliseu Maciel, Universidade Federal de Pelotas, Pelotas, RS.

GALETI, N.C.S. et al. Estaquia de amoreiras submetidas a prétratamento com água e diferentes substratos orgânicos. Scientia Agraria, Curitiba, v.11, n.6, p.451-457, 2010.

HARTMANN, H.T. et al. Plant propagation: principles and practices. 7.ed. New York: Englewood Clipps, 2002. 896p.

LIRA JUNIOR, J.S. et al. Pitangueira. Recife: Empresa Pernambucana de Pesquisa Agropecuária - IPA, 2007. 87p.
LOPES, P.Z. Propagação vegetativa e interação com endomicorrizas arbusculares em mirtáceas nativas do sul do Brasil. 2009. 120f. Tese (Doutorado em Fitotecnia) - Programa de Pós-graduação em Fitotecnia, Faculdade de Agronomia, Universidade Federal do Rio Grande do Sul, Porto Alegre, RS.

NACHTIGAL, J.C. et al. Enraizamento de estacas semilenhosas de araçazeiro (Psidium cattleyanum Sabine) com o uso do ácido indolbutírico. Revista Brasileira de Fruticultura, Cruz das Almas, v.16, n.1, p.229-235, 1994.

OLIVEIRA, M.C. et al. Enraizamento de estacas para a produção de mudas de espécies nativas de matas de galeria. Brasília: EMBRAPA Cerrados, 2001. (Recomendação Técnica n.41). Disponível em: <http://www.infoteca.cnptia.embrapa.br/ handle/doc/566480>. Acesso em: 20 mar. 2011.

PASQUAL, M. et al. Fruticultura comercial: propagação de plantas frutíferas. Lavras: UFLA, FAEPE, 2001. 137p.

SASSO, S.A.Z. Propagação vegetativa de jabuticabeira. 2009. 64f. Dissertação (Mestrado em Agronomia) - Universidade Tecnológica Federal do Paraná, Campus Dois Vizinhos, PR.

SCARPARE FILHO, J.A. et al. Efeito do ácido indolbutírico no enraizamento de estacas herbáceas de jabuticabeira 'Sabará' (Myrciaria jabuticaba) em condições de nebulização. Revista Brasileira de Fruticultura, Jaboticabal, v.21, n.2, p.146149, 1999.

SEAGRI. Cultura - pitanga. Salvador: Secretaria da Agricultura, Irrigação e Reforma Agrária/Governo da Bahia, 2008. Disponível em: 〈http//:www.seagri.ba.gov.br〉. Acesso em: 07 jun. 2011

SOUSA, C.A.F.; SODEK L. The metabolic response of plants to oxygen deficiency. Brazilian Journal Plant Physiology, Rio de Janeiro, BR. v.14, n.2, p.83-94, 2002. Disponível em: <http://www.scielo.br/scielo.php?pid=S 1677 04202002000200002\&script=sci_arttext $>$. Acesso em: 20 mar. 2011. doi: 10.1590/S1677-04202002000200002.

TAIZ, L.; ZEIGER, E. Fisiologia vegetal. Porto Alegre: Artmed, 2004. 719p. (Tradução). 